\title{
Overcoming Word-Centrism: Towards a New Foundation for the Philosophy of Language
}

\author{
Sergey Yu. Boroday* \\ Institute of Philosophy, Russian Academy of Sciences \\ Moscow, Russian Federation
}

Received 23.03.2020, received in revised form 04.08.2020, accepted 11.08.2020

\begin{abstract}
This article attempts to rethink the understanding of language as a "set of words" that correspond to the "objects" of external reality, which is characteristic of Western philosophy and lay perception. The following arguments are offered against this approach: the concept of "word" (like the actual division into morphology and syntax) has no metalinguistic status; the classification of parts of speech is languagespecific, so that the prototypical referential function of a "noun" cannot lay claim to the status of a universal linguistic function; and the idea of language as a "set of words" only reflects the specific metapragmatic awareness of speakers of European languages. Through examining the facts of linguistic diversity and linguistic functions in light of grammatical typology, the author shows that the most adequate interpretation of the relationship between language and reality is an understanding that characterizes language as a large-scale device for forcing its users towards a specific depiction of events. The author also emphasizes the fundamental specificity of the grammatical structure and usage models of each concrete linguistic system. In order to promote a philosophical understanding of language, it is necessary to move from a naïve model that operates with "word - reference - object" to a more realistic model involving "language (as a set of morphosyntactic patterns of conceptualization) - correspondence - event (as a complex situation involving meaning)."
\end{abstract}

Keywords: philosophy of language, cognitive linguistics, linguistic typology, word, reference.

Research area: philosophy.

Citation: Boroday, S.Yu. (2020). Overcoming word-centrism: towards a new foundation for the philosophy of language. J. Sib. Fed. Univ. Humanit. Soc. Sci., 13(8), 1275-1288. DOI: 10.17516/19971370-0641.

(C) Siberian Federal University. All rights reserved

* Corresponding author E-mail address: sergey boroday@inbox.ru 
There is a widespread opinion in philosophy that the referential function of language the function of relating a "word" to the "object" of extra-linguistic reality - is particularly significant. This approach, whereby language is implicitly conceived of as a "collection of words" corresponding to external objects, is also popular in everyday understanding. Using Michael Silverstein's theory one could say that it reflects the "metapragmatic awareness" of speakers of Indo-European languages about how their own linguistic system functions. However, can this view lay claim to universality? The answer to this question is a resounding no. There are several reasons for this.

Firstly, as Silverstein has shown, versions of metapragmatic awareness differ from language to language: the way a speaker of one language understands the mechanisms whereby his language functions are different from how a speaker of another language understands them, although here one can also identify certain universal semiotic tendencies ${ }^{1}$. Hence it follows that a speaker of a language with a fundamentally different structure would probably identify as significant functions that do not seem relevant for speakers of European languages (or which simply have no analogy in them).

Secondly, reference in the classic sense reflects the basic function of the noun, whereas the linguistic system also contains other parts of speech that fulfill other functions; even if one recognizes that the function of the noun is prototypical, a doubt still arises concerning the possibility of interpreting it as a universal linguistic function because, as Leonard Talmy has shown, there is an important typological difference between object-dominant and action-dominant languages, that is, between languages that use prototypical nouns to denote objects and substances and languages that use prototypical verbs for these ends (cf. "Hailstones came in through the window" vs. "It hailed through the window") $)^{2}$. One must add,

\footnotetext{
1 Silverstein, Michael (1981). The Limits of Awareness. In Working Papers in Sociolinguistics. No. 84. Austin: Southwestern Educational Laboratory.

2 Talmy, Leonard (2000). Toward a Cognitive Semantics. Vol. I: Concept Structuring System. Cambridge, MA: MIT Press, P. 43-46.
}

too, that it is doubtful whether the "noun" is a universal metalinguistic category.

Thirdly, although motor interaction with "things" plays a huge role in the process of ontogenesis, the concept of "object" as it forms in the adult consciousness is not independent of language but acts as a complex perceptual-conceptual-linguistic construct that differs from language to language and from culture to culture. Consequently, one cannot automatically use it to describe a universal linguistic function.

Fourthly, the actual concept of "word" cannot lay claim to metalinguistic status but is a language-specific concept (see below for more on this).

This represents only part of the arguments that could be adduced against an understanding of the essence of language as being a correspondence between "words" and "objects". If this understanding is limited and circumscribed by linguistic ideology of a certain type, how should one approach the problem of language in such a way as to attain a maximally broad perspective? In this article, an attempt will be made to briefly examine this problem in light of some typological variations that we are familiar with. We will attempt to show that understanding language as a "set of words" and cross-language differences as differences in the classification of words and their meanings is wrong. In fact, 1) the concept of "word" (like the division into morphology and syntax) has no metalinguistic status but is applicable only to a specific language; 2) every language comprises an original classification of meaningful elements ("parts of speech") that must be examined on the basis of criteria applied to the language in question, with due consideration of language-internal relations; 3) the difference between the lexical and the grammatical is also language-internal; 4) grammaticality in the broad sense includes lexical, discursive and referential obligatoriness, and the combination of all the types of obligatoriness forms the unique rhetorical style of language; 5) in the final analysis, language, due to limitations imposed by it on the means of expression, must be understood as a large-scale device for forcing its users towards a specific depiction of events. 
In considering these theses, one can make the following conclusion, which is important for the philosophy of language: one must move from a naïve conception of language as a correspondence between "words" and "objects" to the idea of language as a set of morphosyntactic structures and usage models that have a limited and mandatory character and that do not correspond to discrete "objects" but rather to complex events, which are subject to a different implicit conceptualization depending on features of the concrete linguistic system. This scheme allows one to better understand the nature of language and the way it really functions. Moreover, it follows from this that in the philosophy of language (at least at first) the emphasis should be placed on a typology of linguistic functioning based on actually existing natural languages and not an abstract "language as such", which is all too often just an eviscerated and lifeless version of the researcher's native language, which is nearly always Indo-European (and in our time, English) ${ }^{3}$.

\section{The word}

In psychology, philosophy and many other fields of the humanities, the concept of "language" has a solid association with the concept of "word". A similar association can also be observed in everyday understanding. The general idea could be expressed as follows: language is words and words are denotations of objects; as a set of words language lies somewhere between thought and objects. It is noteworthy that a similar model was developed as far back as Aristotle. The theory of reference, from medieval thinkers up to Chalmers, also works with the "word". The titles of major treatises in philosophy often include the concept of "word": one need only recall Quine's "Word and Object" or Foucault's "Words and Things" ("Les

\footnotetext{
3 In this article we present in general form ideas that were argued for in detail in our monograph devoted to the problem of linguistic relativity and the question of the place of language in the cognitive architecture: Boroday, Sergey (2020). Iazyk i poznanie: Vvedenie v Postrelativism [Language and Cognition: An Introduction to Post-Relativism]. Moscow: OOO "Sadra", LRC Publishers. An English summary of the main ideas appears in the book in Appendix No. 2 and can be accessed at https://www.academia.edu/42617503/Language_and_Cognition_A_Post-relativist_Research_Program
}

mots et les choses"). All this definitely has a certain intuitive clarity. However, the problem of the "word" - when translated into the professional linguistic and typological dimension - is not as simple as might seem at first glance. Let us begin with the fact that the actual meaning of "word" is absent in cultures of the archaic type 4 . In European languages the designation for "word" developed from the designation for "name" or "utterance" (Rus. slovo, Eng. word, Fr. mot; in Proto-Indo-European there was the lexeme *h nomn - "name", but there was no lexeme meaning "word").

In many Structuralist schools, "word" was not a part of formal analysis. Throughout the $20^{\text {th }}$ century, numerous formal definitions were proposed but none of them was completely satisfactory. The reason lurks in the fact that by all accounts there simply is no universal definition. However, if that is the case, then the concepts of "morphology" and "syntax" are problematic, as both of them are defined using the "word". If one looks at the concept of "word" from the viewpoint of typology, it appears that there are no reliable criteria for identifying it as a metalinguistic concept. None of the criteria put forward in the literature (potential pauses, free occurrence, external mobility and internal fixedness, uninterruptibility, non-selectivity, non-coordinatability, anaphoric islandhood, non-extractability, morphophonological idiosyncrasies, deviations from biuniqueness) can be considered universal ${ }^{5}$. Given that we are talking of the formal, or grammatical, status of "word", phonological criteria should not play a decisive role in this instance.

If "word" is not a universal concept, it might be a language-specific component. This possibility was examined by certain structuralists. The term "word", in this case, potentially has as many meanings as there are languages; this would also be true of the terms "morphology" and "syntax". Roughly speaking, "word" is an element occupying

\footnotetext{
4 Dixon, Robert, Aikhenvald, Alexandra (2002). Word: A typological framework. In Word: A cross-linguistic typology. Ed. by R.M.W. Dixon, A. Aikhenvald. Cambridge: Cambridge University Press. P. 3.

5 Haspelmath, Martin (2011). The indeterminacy of word segmentation and the nature of morphology and syntax. In $\mathrm{Fo}$ lia Linguistica, 45 (2), P. 31-80.
} 
an intermediate position between the minimal sign and the phrase. Although this approach has meaning when analyzing a specific language, on the typological level it is better to emphasize minimal morphosyntactic combinations with different degrees of tightness, while examining the specifics of each of these combinations using the example of each particular language. One can agree with Martin Haspelmath's conclusion that concepts like "word", "morphology", and "syntax" are not too relevant for linguistic typology $\mathrm{y}^{6}$.

On the other hand, the attribution to the word in traditional conceptions of purely orthographic reality is too bold a step. Despite the fact that from the perspective of grammatical typology the language-specific interpretation of "word" does not make much sense, it is relevant for psycholinguistics and semantics.

This is supported, on the one hand, by the data concerning aphasia, and on the other hand by native speaker's intuitions. Even uneducated people feel that there are complex and stable elements that are located in the morphosyntactic continuum between the morpheme and the phrase. In different languages the set of such elements is different, and even within a single language several variations are possible here. However, in all cases there are elements that have a certain propositional and psychological relevance for the speaker. This is what language-specific "words" are.

From the propositional point of view the "word" is an element fitted for prototypical reference. This fitness is probably linked to the realities of language acquisition. First acquired are complexes of signs which are best suited for reference. They comprise a basic foundation, which is stored in the memory and which is used at the holophrastic (word-sentence) stage. Next, using regularities in these complexes and under the influence of external speech we see the abstraction of what is usually called "grammar". In a later period, children can already independently fill out missing forms, which is connected with the active insertion of grammar into cognition. Thus, the initial content acquired by the child reflects the referential

\footnotetext{
6 Ibid. P. 62.
}

practice of a given community. Unfortunately, it is impossible to trace the evolution of referential practice directly. The question of why certain complexes are used as minimal in certain communities while others proceed differently is connected with the problem of language development, particularly the theory of grammaticalization.

From the psychological point of view, the "word" is an element that forms the basis of linguistic memory. In taking this definition on board, one should bear in mind that linguistic memory is language-specific. For example, speakers of synthetic languages remember not just words but also phrases, constructions, idioms, separate affixes and so on. However, the nucleus of this memory is actually made up of "words", that is, elements acquired for prototypical reference. The psychological status of the word might also be influenced by non-linguistic factors. These are capable of increasing/decreasing the psychological relevance of the word or other combinations of morphemes.

Thus, although from the perspective of grammatical typology the concept of "word" is not relevant, one can still speak of the "word" in the psycholinguistic and semantic sense. Still, one must keep in mind that one is always speaking of a language-specific concept.

\section{Parts of speech}

The basic classification contained in language is the division of meaningful language-specific elements into parts of speech. The expression "parts of speech" is a calque from the Latin pars oratiōnis. In English-language literature now the most widespread terms are lexical categories and word classes. These terms are believed to better capture the desired meaning. Actually, by parts of speech one should understand an implicit group of meaningful elements which is formed intuitively by speakers and expressed in the linguistic system at the grammatical level. As a rule, the problem of parts of speech is linked with the problem of word divisions, as the classified elements are most commonly language-specific words. However, in some cases the basic element might be a morpheme; in principle 
one can posit classifications which also include roots, affixes and combinations of morphemes, so that recognizing the reality of parts of speech does not always involve recognizing words and does not always require a clear-cut definition of the "word".

All languages are based on an implicit categorization of meaningful elements. Put differently, there is no language in which words or morphemes could be completely homogenous on the functional level, that is, in which they could potentially receive all possible morphological, syntactic and distributional characteristics. Nonetheless, languages differ in how they make internal demarcations in the lexical sphere: from dozens of categories to several categories. The principles of internal division are also different: for example, meaning conveyed with a "noun" in one language might be encoded with a "verb", "adjective", and so on, in another. At the same time the concept of "noun", "adjective" and "verb" are used here only in an approximate sense, as there is every reason to believe that these categories are language-specific. The potential uniqueness of internal categorization makes the question of parts of speech extremely topical.

Turning now to the history of the study of parts of speech, we see a solid Eurocentrism, which to this day has not been overcome. Among Western thinkers a preliminary classification had already been made by Plato and Aristotle, and this was later perfected by Hellenistic scholars, especially Chrysippus and Dionysius Thrax. In professional linguistics, beginning with the Humboldtian school and ending with structuralism, a belief in the language-specificity of parts of speech was dominant, while the development of the generative school can be seen as reviving the universalist interpretation. In early generative grammar the question of how to identify parts of speech was not even posed, as it was accepted $a$ priori that the division into noun, verb and adjective exists in all languages (if one does not assume this division, nearly all the syntactic structures with a claim to universalism proposed by Noam Chomsky are irrelevant). To this day the universalistic interpretation is dominant in this branch ${ }^{7}$. It is worth mentioning that in functional typology since Joseph Greenberg comparative "parts of speech" are interpreted semantically, rather than formally and grammatically. Modern typologists and authors of grammars (though not all of them) use the concepts of "noun", "verb" and "adjective", but hardly anyone believes that a "verb" in English is the same thing as a "verb" in Nootka or Adyghe. Thus, the use of these terms reflects tradition and their meanings are conditional, although also connected to a propositional-referential prototype. It is important to understand that the use of terms like "verb" and "noun" often involves an implicit comparison with the researcher's native language, and this can allow a distortion of the realities of another language when describing it. That is why it seems more consistent to take the position of typologists who emphasize the language-specificity of these categories and insist on the necessity of identifying and describing them using the internal relations in a given language. This neostructuralist tendency has become particularly prominent in recent years. ${ }^{8}$

There are several criteria for identifying parts of speech in a particular language. Most attention had been given in linguistics to morphological, syntactic and semantic criteria. In fact, the most adequate classification within a particular language involves a combination of several criteria. Primarily, it should consider native speakers' intuition which, as a rule, senses the functional heterogeneity of words/ morphemes stored in memory. It is precisely this feeling that lies behind the traditional classifications: the European model essentially reflects the realities of Indo-European languages, while other linguistic traditions - for example, the Japanese and Chinese - reflect the realities of the languages on which they are based. Heterogeneity of words is also confirmed by

\footnotetext{
7 Cf., for example., Baker, Mark (2002). Lexical Categories: Verbs, Nouns, and Adjectives. Cambridge: Cambridge University Press.

8 Cf.: Haspelmath, Martin (2012). How to compare major word-classes across the world's languages // UCLA Working Papers in Linguistics, Theories of Everything, 17, 109-130; Hengeveld, Kees, van Lier, Eva (2008). Parts of speech and dependent clauses in Functional Discourse Grammar. In Studies in Language, 32 (3), P. 753-785.
} 
the data of aphasia. Morphological and syntactic criteria then need to be combined with the psycholinguistic criterion. However, in every concrete case the value of the latter two criteria is relative, so that one can say that the identification criteria for lexical categories are themselves language-specific. Thus, in Nahuatl the noun and the verb receive a strong morphological, but not a syntactic, differentiation; in Kabardian and the Salish language, Comox, this opposition can be observed but it is weakly marked; in the Tahitian language it is characterized by small differences in morphology and syntax, although syntactic differences can be neutralized; in the Iroqoian language Cayuga there is a difference at the root level, which is neutralized in incorporations; in Tagalog this difference is absent at the syntactic level but fairly noticeable in the morphology.

If one consistently applies several identifying criteria, parts of speech, or psychologically and grammatically meaningful groups of lexemes, can be observed in any language. As has already been noted, there are no languages in which morphemes/lexemes are completely homogenous in the functional sense. However, there are languages which get close to this "ideal" - at least in the sphere of categorematic words. Such a model has been proposed, for example, for Archaic Chinese?

So implicit classifications of lexemes are language-specific and the criteria by which these classifications are produced are also language-specific. What then do the terms "noun", "verb" and "adjective" mean? And in what sense can one speak of the existence of "nouns", "verbs" and "adjectives" in specific languages? Earlier we noted that the use of these terms for metalinguistic analysis is conditional as no one really believes that these categories refer to the same thing in all languages. If we look at these concepts as metalinguistic, we stumble on the rather absurd situation noted by Haspelmath: formulas like "Does this language have adjectives?" or "Do all languages have a difference between nouns and verbs?" are simply meaningless. They are comparable to questions like

\footnotetext{
9 Bisang, Walter (2008). Precategoriality and Argument Structure in Late Archaic Chinese. In Constructional Reorganization. Ed. by J. Leino. Benjamins, P. 55-88.
}

"What is the order of inheritance to the German throne?" and "How many states are there in France?"10. Division into parts of speech is completely language-specific, although one can also identify several general "informal" tendencies ${ }^{11}$.

One needs to move from the problem of "word classes" as categories to the problem of "morpheme classes" as comparative concepts. The definition of these classes must be established on a semantic basis, while also partly using propositional criteria. It is this position that is taken by William Croft ${ }^{12}$. According to Croft, "verb", "noun", and "adjective" are typological prototypes that can be described using semantic and propositional criteria: the prototype of a noun is characterized by object semantics and referential function, the prototype of a verb is characterized by a semantics of action and the predicative function, the prototype of an adjective is characterized by the semantics of quality and the function of modification. It seems to us that this approach is acceptable if we exclude "adjective" from the prototypical concepts, as this concept is not universal and its semantics is rather vague.

Evidently, the universality of the prototypes of the noun and verb is linked to the cognitive prominence of stable objects and transitory actions. From a general typological perspective there is the following tendency: we see a class of lexemes whose core comprises denotations of stable objects and plays a crucial role in the act of reference, and a class of lexemes whose core comprises denotations of actions and plays a crucial role in the act of predication ${ }^{13}$. Sometimes these differences are

\footnotetext{
${ }^{10}$ Haspelmath, Martin. How to compare major word-classes across the world's languages.

${ }^{11}$ However, the actual division into "form" and "semantics" is not clear-cut and universal. In psycholinguistics the formal "expression" of meaning for a native speaker is also significant (cf. in this regard the extensive discussion on "grammatical semantics" and "codability"). But this is a separate topic which we won't dwell on here.

${ }^{12}$ Croft, William (2001). Radical Construction Grammar Syntactic Theory in Typological Perspective. Oxford: Oxford University Press.

${ }_{13}$ We are speaking here only of a tendency. The real picture might be very different from the general scheme - and here one should mention the typological breakdown of languages proposed by Talmy into object-dominant and action-dominant.
} 
barely noticeable, but there is still not a single language which lacks them entirely. Some authors propose to talk of a bipolar continuum whose poles are made up of a prototypical "noun" and a prototypical "verb". Between the two poles other categorematic classes are located, and considerable variation is possible within this interval. There have been attempts to describe languages using this "non-discrete" understanding of parts of speech: for example, in this approach the Australian language Murrinh-patha is said to contain, in addition to nouns, adjectives and verbs, verb-nouns (vouns) and noun-verbs (nerbs) $)^{14}$, while Cayuga has six intermediate categories in addition to its nouns and verbs ${ }^{15}$. It seems to us that on the descriptive level the continual understanding of lexical classes is the most suitable.

Thus, parts of speech, or grammatical groups of lexemes/morphemes must be identified for specific languages on the basis of several criteria. Preference for certain approaches to identifying lexical categories depends on the structure of the language, so that the choice of an approach is language-specific. The parts of speech themselves are completely language-specific, although there are always limits on variation, and they are best described using the concept of a bipolar continuum. Comparative analysis of parts of speech is impossible, as they are incommensurable at the structural level. A common field of analysis includes "denotational" semantics and the type of proposition. Thus, every language presents an original classification of meaningful elements which must be examined on the basis of criteria applying to the language in question and taking into account internal linguistic relations.

\section{Functional structure}

Above we emphasized that natural language is characterized by a unique internal categorization: such categorization assumes,

\footnotetext{
${ }_{14}$ Walsh, Michael (1996). Vouns \& nerbs: A category Squish in Murrinh-Patha (Northern Australia). In Studies in Kimberley languages in honour of Howard Coate. Ed. by W. McGregor. München. P. 227-252.

${ }^{15}$ Sasse, Hans-Jürgen (2001). Scales between nouniness and verbiness. In Language typology and language universals: An international Handbook. Vol. 1. Ed. by M. Haspelmath et al. Berlin; New York. P. 498-499.
}

on the one hand, the formation of psychologically meaningful complex elements ("words"), which are located on a morphosyntactic continuum between the morpheme and the phrase; and on the other hand, it assumes the grouping of lexemes according to grammatical class. The characteristics of the typical word, the principles of grouping, and the results of grouping all depend on the specific language. Now we will examine another important feature of natural language - functional structure, or grammar. Grammaticality can be interpreted in at least two ways: in the narrow sense it means a grammatical system, that is, a system formed by meaningful elements whose main feature is obligatoriness; in the broad sense, grammaticality in language is anything that is needed for expression.

Formal grammaticality, or grammaticality in the narrow sense, is the skeleton of the linguistic system. The problem of separating the grammatical from the non-grammatical is complex. It is a subject for discussion in theoretical linguistics and there are no generally agreed upon criteria here. This situation is undoubtedly connected not so much to the theoretical feebleness of linguists as to real linguistic diversity: criteria that are suitable for languages of one structure are often absolutely inadequate for languages of another structure. Nonetheless, it seems that the most pragmatically suitable definition of grammaticality is the definition of Franz Boas. In his opinion, the main characteristic of grammatical meaning is obligatoriness. Grammatical meaning, unlike lexical meaning, cannot not be expressed, and furthermore, what characterizes obligatoriness is not so much the particular meaning as the grammatical category as a whole. Lexical meaning as opposed to grammatical meaning is not obligatory and categorical. A meaning that is grammatical in one language will certainly not always be grammatical in another language. From the theoretical point of view any semantic domain can be grammaticalized, that is, any collection of homogenous meanings can take on the features of categoricality and obligatoriness. For example, in the North American language Nootka grammatical features are given to the meaning "physical flaw 
of the subject (= a type of deformity)"; the expression of this meaning takes place through a special suffix which is attached to the verb, with phonetic changes also sometimes occurring within the word-forms. The following meanings are included in the grammatical category: "normal", "fat", "small", "crooked/ bent", "hump-backed", "lame", "left-handed"16. In addition to the grammaticalization of exotic semantic fields, one should also note the existence of several exotic grammemes within completely typical grammatical categories. For example, in Kwak'wala we find the evidential marker "to dream something", in Korafe there is an absolute tense (or type of temporal distance) meaning "between yesterday morning and today" and in Anindilyakwa we find a grammaticalized noun class which includes only objects that reflect light. Cases of exotic grammemes within a typical semantic domain are fairly common, while cases of the grammaticalization of exotic semantic fields are rare and usually require further investigation. In grammatical typology, the dominant opinion is that there are universal semantic domains that undergo grammaticalization: in more moderate form this idea implies the existence of general tendencies in the grammaticalization of different fields.

Therefore, the main feature of grammatical meaning is obligatoriness. A grammatically expressed concept is used automatically and unconsciously. The difference between the grammatical and non-grammatical status of a concept implies a whole group of cognitive oppositions: used vs. pondered, automatic vs. controlled, unconscious vs. conscious, effortless vs. effortful, fixed vs. novel, conventional vs. personal ${ }^{17}$.

In linking grammaticality to obligatoriness one should bear in mind that obligatoriness is gradual. Evidently, one can speak of a scale of obligatoriness, on which different grammatical meanings are located. For example, the category of tense in the Russian verb

\footnotetext{
16 The classic study on this topic is: Sapir, Edward (1949). Abnormal types of speech in Nootka. In Sapir, Edward. Collected Writings of Edward Sapir in Language, Culture and Personality. Berkeley: University of California Press. P. 179-196.

17 Lakoff, George (1987). Women, Fire, and Dangerous Things. Chicago: University of Chicago Press. P. 320-322.
}

has less obligatoriness than the category of mood, as tense must only be expressed in the indicative mood. Grammatical obligatoriness is sometimes subject to limitations. It can be blocked by another grammatical category: so in Russian, present tense blocks the expression of gender, while past tense blocks person. Grammatical meaning can also be blocked by lexical features: for example, in Russian not all verbs have a perfect aspect, and in English not all verbs are used in the present continuous. Finally, a grammeme can be blocked by discursive and cultural circumstances. Thus, in calling the principle of obligatoriness the main feature of grammatical meaning, one should remember that it rarely manifests in its complete type and that this is linked to deviations that are present in any linguistic system. Formal grammaticality must be defined for each language separately. This thesis is fair, too, for the semantics of grammemes, as grammemes always have polysemous and functional features. This is even more relevant for the manner in which grammemes are expressed, as there are hardly any identical manners of expression for all languages, and it is not even clear what would be meant by "identical" if, as we have already noted, formal categories must be defined from language-internal relations.

In addition to the type of obligatoriness just examined, there is also what might be called lexical obligatoriness. Lexical obligatoriness is an effect of categoricality and the creativity of denotation. As language classifies and structures experience in a specific manner, it invariably imposes lexical limitations on ensuing conversations about the world. For example, the domination in the Australian language Guugu Yimithirr of an absolute frame of reference ("north"/“south", "east"/“west") makes a description of spatial relations in terms of a relative frame of reference impossible, forcing its users to use lexis of an absolute type. The presence in many languages of the color term "green-blue" ("grue") without separate terms for "green" and "blue" forces a user to describe both colors identically. The absence of a word for "child of the same parents" forces Russian speakers to specify whether this means a "sister" or a "brother", while English speakers who 
actively use the word "sibling" do not have to do this. In most cases language does not determine speech fully as descriptive formulas or paraphrases can be used. Still, language allows one to automatically and actively use the meanings that exist in the lexical set. Paraphrase involves further reflection and a cognitive load, so that it is required only in specific circumstances. One should add that very often one encounters an even deeper form of limitation: a language might totally lack the means to express certain concepts. So in languages with a defective numeral system ("one"/ "few"/ "many") precise numerical meanings cannot be expressed. In languages with a two-part color system ("light"/ "dark") many colors from the Munsell color system cannot be given stable names. A number of languages lack abstract concepts like "tree", "plant", "animal", "instrument" and so on. Interestingly, even when such concepts are present there are different strategies for naming sub-types included in the category: in Russian and English an unknown plant will be designated as "plant", while in Upper Chinook a hyperonym cannot be used for hyponymic meaning, and it will simply remain unnamed. Thus, examples of lexical obligatoriness are highly diverse. Lexical obligatoriness is a logical effect of limitations on forms of expression. Generally, one can represent it in three forms: the necessity of making additional demarcations ("brother" or "sister" vs. "sibling"); the impossibility of making additional demarcations ("grue" vs. "blue" and "green"); and the impossibility of saying something ("to the right of the house" or "pink").

In addition to formal-grammatical and lexical obligatoriness there is also discursive obligatoriness. Discursive obligatoriness implies that one particular meaning and no other should be used in a particular situation. It relates to how the linguistic system is embodied in real speech practices. If we understand "language" in a maximally broad sense, discursive obligatoriness is connected with its usage and is a part of language. The simplest example can be found in Russian where there are two forms of the $2^{\text {nd }}$ person singular pronoun, "ty" and "Vy". As is well known, the pronoun "Vy" is more polite and is used for respected or un- known people. Shifting to "ty" in certain situations can produce disrespectful or even aggressive connotations. In using "ty" or "Vy" the Russian speaker demonstrates his relationship to the interlocutor. This sort of discursive obligatoriness is not an issue for speakers of English, which lacks the $2^{\text {nd }}$ person singular polite form. In Japanese, Javanese, Acehnese and other languages, there are three degrees of politeness, which are expressed not just in the system of pronouns but in other lexis as well. There is a situation in which in nearly every utterance the speaker must express his relationship to his interlocutor (usually, pejorative, neutral or respectful). Discursive obligatoriness is also manifested in situational and sociolectal limitations: the speaker must adapt his speech to the status, degree of familiarity with the people around him, and degree of formality of the event. In many languages there are "female" sociolects with special grammatical and lexical features. In Indo-Aryan languages there is evidence of caste sociolects which have special phonetic features. In Australian languages there are many special forms used in the presence of the parents of one's wife or husband (so-called "avoidance languages"). Discursive obligatoriness often affects grammatical categories. A good example is Upper Chinook, in which a future tense of the perfect form can only be used if the speaker can vouch that the event will take place; in other situations a future tense of a non-perfect type must be used. We have given only a few possible examples, which clearly attest to the fact that language is not simply a categorical system of meaningful elements, but also an understanding of how meanings should be realized in speech practice.

To these types of obligatoriness we also need to add referential obligatoriness. Reference - at least, the real reference that is familiar to us from our own experience - always takes place within the framework of a particular language and on the basis of a particular language $^{18}$. The language-specific nature of reference has several dimensions. Firstly, we always start from the lexical-morphemic set given by language. To say that this tree is a "tree"

\footnotetext{
${ }^{18}$ Here we understand the word "reference" in the broad sense - as "correspondence" to non-linguistic reality.
} 
is already to use an existing designation. This situation is not that simple when one considers that one cannot replace a hyponymic meaning with a hyperonym in all languages (as mentioned above). Another aspect of naming a tree a "tree" is that as speakers of a synthetic language (e.g. Russian) we are using a lexeme consisting of a stem and ending, a lexeme which is also in the nominative case and neuter gender (Rus. derevo). We are also using a lexeme of a particular class, the class of nouns. Finally, we are using the lexeme, "word", that is, an element that is psychologically significant for us, which occupies an intermediate place between the morpheme and phrase in the morphosyntactic continuum. Referential obligatoriness is derived from the language-specificity of any utterance. It consists of the fact that reference implicitly involves the whole structure of the language. In discussing the correspondence between "words" and "things" one always needs to specify which language is being implied. The particular nature of reference might require from the speaker of that language to express not case or gender but, for instance, tense and the form of the noun (as in the case of nominal tense, noun classes and numeral classifiers). Despite the fact that reference is prototypically connected with "nouns", it is permissible to have situations where use of a "noun" is blocked; in that case, one cannot speak of a tree as a "tree", but one has to say, for example, "to be a tree", or "to tree". Ivanov gives a similar example: "A native American who was teaching me the Iroquois language Onondaga refused to translate the English word tree, saying that a morpheme with such a meaning exists only as part of the verbal form" 19 . Considering the language-specific nature of "word", reference can include from one to several morphemes everything depends on how complex a typical "word" is in a particular language. In general, variations in this field are many. Different languages push one towards different models of reference, so that to speak unreflectively of unqualified reference, of "reference in general", would mean to involuntarily universalize refer-

\footnotetext{
${ }^{19}$ Ivanov, Vyacheslav Vsevolodovich (2004). Lingvistika tret'ego tysiacheletia [Linguistics of the Third Millenium]. Moscow: LRC Publishing. P. 52.
}

ence, basing oneself on the researcher's native language. Unfortunately, this is the very path that many theoreticians have chosen since the times of Plato and Aristotle.

Thus, the meaningful elements of a linguistic system are not homogenous in the functional sense. They are characterized by different degrees of obligatoriness and conventionality. The types of obligatoriness presented above are linked to each other and it is not always easy to subsume a particular example to a particular group. The combination of all types of obligatoriness forms the unique rhetorical style of a language.

\section{Conclusion:}

\section{towards a reflective philosophy of language}

So what understanding of language does the above analysis lead us to? In what follows we will summarize in thesis form some ideas that sketch an understanding of "language" which takes account of the real breadth of typological variation and can become the basis for a reflective philosophy of language:

- Language can be understood as the internal organization of meaningful elements which enables the categorization of external experience, i.e. its conceptualization; this formulation does not prevent the existence of many other definitions of language, as any definition emerges from the position from which we look at the phenomenon.

- Languages organize meaningful elements differently, and the content of these elements is also specific to each linguistic system.

- Designation is the categorization of experience; categorization implies abstracting over several features, schematizing them, identifying the prototype, forming a particular category and its opposition to other categories.

- Languages do not just interact with previously given domains of experience but are also capable of constructing original semantic spaces; in other words, in a number of cases, designation is creative.

- Creativity and categoricality of designation result in the uniqueness of several meanings; such meanings cannot be fully conveyed in another language; however, one cannot rule out the fact that any meaning in any language - 
due to its unprecedented distribution - is psychologically unique.

- The semantic dimension of language includes both categorization and partial construction; furthermore, it is dynamic, hierarchical and non-homogeneous; all this results in the originality of semantics in every language.

- Dynamism, hierarchy and non-homogeneity of the semantic dimension is established by what is usually considered the formal aspect of language, or internal form; there is every reason to assert that every language is characterized by a unique immanent structure.

- Of particular psychological relevance for the native speaker is the element located in the morphosyntactic continuum between the morpheme and the phrase; from the propositional point of view, this element - the word is a unit comprising the main basis of linguistic memory; on the formal level the "word" is completely language-specific, just as the opposition between morphology and syntax is also language-specific.

- The basic classification embedded in a language is the division of language-specific words into parts of speech, or lexical categories; to identify parts of speech in a particular language requires a combination of several criteria; firstly, one needs to consider the intuitions of native speakers who, as a rule, sense the functional non-homogeneity of the words/morphemes stored in memory; psycholinguistic criteria should be taken together with morphological and syntactic criteria, but the optimal relationship between these criteria depends on the structure of a particular language; from the typological perspective significant parts of speech (or categorematic words) are best described using a bipolar continuum.

- In addition to the implicit grouping of lexemes, each language has an internal functional organization, which involves formal grammaticality, lexical obligatoriness, discursive obligatoriness and referential obligatoriness.

- Formal grammaticality is enabled through a set of grammatical categories formed by a series of mutually exclusive meanings, or grammemes; meaning which is grammatical in one language may not be grammatical in another; theoretically any semantic domain can be grammaticalized in any language, but there are general tendencies in the grammaticalization of certain fields; the opposition between grammatical/non-grammatical should be thought of as gradual; in addition, grammatical obligatoriness is sometimes subject to lexical, formal, discursive and cultural limitations; all these factors should be looked at separately for each language, as the organization of grammatical meanings is language-specific.

- Lexical obligatoriness is an effect of the categoricality and creativity of denotation and is conditioned by limits on the means of expression; in the most general sense it can be conceived of in three forms: the necessity to make additional demarcations, the impossibility of making additional demarcations, and the impossibility of saying something in a particular language.

- Discursive obligatoriness concerns how the linguistic system is realized in real speech practices; it means that in a particular situation precisely this meaning should be used and no other; discursive obligatoriness involves both separate lexical-grammatical meanings as well as whole sociolects.

- Referential obligatoriness derives from the language-specific nature of any utterance; it consists of the fact that the act of reference implicitly involves the whole structure of the language; real reference is always realized within a particular language and using its tools.

This sketch differs sharply from the popular opinion of language as a set of "words" that are linked to "objects" in the outside world. The understanding of language in the context of a correspondence between "word" and "object" (what one might call the onomathetic metaphor, or "word-centrism") is an essential distortion of the real situation. On the basis of the ideas presented above, one must take a different viewpoint. From this perspective language can be characterized as a large-scale device for forcing its users towards a specific depiction of events. Language forces one to express an event through the use of limited means, and compels one to construct and conceptualize each event in a special manner. This is the rhetorical style 
of a particular language or, in Whorf's words, its fashion of speaking ${ }^{20}$. It is important to emphasize that we do not simply mean the use of specific lexemes or a unique model for relating lexemes and objects/situations. Rhetorical style is formed on the basis of the organization of meaningful elements in language as a whole, and this organization concerns basic components like "word", "morphology", "syntax", "parts of speech", "obligatoriness", "functional application", and so on. When we emphasize the specificity of rhetorical style, we mean its fundamental specificity, which concerns the whole structure of a given language - from "word" to the idiomatic means of expression used in concrete speech situations ${ }^{21}$. Thus, every language presents a unique and limited model of categorization, construction and description of the field of sense.

What does this mean for philosophy? First and foremost, one must accept that, when looking at the essence of language, it is wrong to start from the idea of a correspondence between "words" and "objects". Undoubtedly, every language in some way corresponds to the world, but the nature of this correspondence is different from the simplified picture depicted in the classic approach. Firstly, a language corresponds not to discrete objects (and even ontogenetically this correspondence is not universal, as attested by the fact that the process of acquiring a language depends heavily on its lexical-grammatical structure) but to complex events (or situations), which can be divided and understood in an objective, processual, singular, discrete manner, through the use of different models of action and causality, and so on - the rich illustrative material concerning this problem can be found in the works of cognitive linguists (cf. the diversity of construal operations); in other words, in language itself the method of imagining what language corresponds to possesses the features of constructivity. Secondly, in the act of correspondence a big role is played

\footnotetext{
${ }^{20}$ Whorf, Benjamin Lee (1956). Language, Thought, and Reality. Cambridge: MIT Press. P. 158-159.

${ }_{21}$ This fundamental specificity has been conceptualized in any detail in only one theory of language, which also takes account of the breadth of typological variation - namely, the Radical Construction Grammar of William Croft.
}

by features of the particular language - the models contained within it for categorizing experience, dividing elements by degree of tightness, language-specific criteria for identifying words, parts of speech, patterns of formal, lexical, discursive and referential obligatoriness; in other words, what is important is that organization of meanings and usage models are imposed by a particular language (of course, the degree of imposition differs depending on what component of language we are considering). Thirdly, the very character of correspondence between language and event can differ from language to language, which is a result of the permanent influence of language on cognitive operations, especially selective attention, perception, working memory, and so on. In other words, language in some sense forces us to choose and submit to categorization that with which (and how) it must be brought into correspondence. Thus, in the schema "language-correspondence-event" language-specificity is relevant for all three components. In addition, from the above it should be evident that the linguistic sign - due to its involvement in a network of heterogenous and multifunctional relations within the linguistic system - cannot be understood as a particular instance of a more general conception of the sign - at least without damaging its essential features. Despite Saussure, linguistics is not a part of semiotics.

Let us once more emphasize this: we are looking at the real situation of how the act of relating language and reality takes place, that is, we are trying to identify the most general and universal features that characterize this act. In this regard the question may arise: is it right to limit the philosophical position to the position of the speaker of one particular language or is a person capable in principle of overcoming the limitations imposed on him by a specific natural language and to understand the essence of language in general? This must be answered as follows. Of course, to limit one's philosophical position - by definition, a position that strives for universality to the position of the speaker of one particular language is wrong. But this is exactly what the whole of European philosophy has been doing 
throughout its history. The typical Western theorist judges the essence of language unreflectively, looking at this essence in connection with the naïve schema of "word-object". The reflective position consists in fact of looking at the function of language from a broader typological perspective. It then turns out that humanity in principle is capable of overcoming the limitations imposed on it by its par- ticular native language (or several languages), and of posing the question of the essence of "language as such" - of what is characteristic of natural language as language. However, this has not yet been done in the philosophy of language. We hope that the first steps in this direction, which have been outlined in this article, will ultimately lead to a more perfect understanding of the nature of language.

\section{References}

Baker, Mark (2002). Lexical Categories: Verbs, Nouns, and Adjectives. Cambridge: Cambridge University Press.

Bisang, Walter (2008). Precategoriality and Argument Structure in Late Archaic Chinese. In Constructional Reorganization. Ed. by J. Leino. Benjamins. P. 55-88.

Boroday, Sergey (2020). Jazyk i poznanie: Vvedenie v Postrelativism [Language and Cognition: An Introduction to Post-Relativism]. Moscow: OOO "Sadra", LRC Publishers.

Croft, William (2001). Radical Construction Grammar. Syntactic Theory in Typological Perspective. Oxford: Oxford University Press.

Dixon, Robert, Aikhenvald, Alexandra (2002). Word: A typological framework. In Word: A cross-linguistic typology. Ed. by R. M. W. Dixon, A. Aikhenvald. Cambridge: Cambridge University Press. P. 1-41.

Haspelmath, Martin (2012). How to compare major word-classes across the world's languages. In UCLA Working Papers in Linguistics, Theories of Everything, 17, 109-130.

Haspelmath, Martin (2011). The indeterminacy of word segmentation and the nature of morphology and syntax. In Folia Linguistica, 45 (2), P. 31-80.

Hengeveld, Kees, van Lier, Eva (2008). Parts of speech and dependent clauses in Functional Discourse Grammar. In Studies in Language, 32 (3), P. 753-785

Ivanov, Vyacheslav Vsevolodovich (2004). Lingvistika tret'ego tysiacheletia [Linguistics of the Third Millenium]. Moscow: LRC Publishing.

Lakoff, George (1987). Women, Fire, and Dangerous Things. Chicago: University of Chicago Press.

Sapir, Edward (1949). Abnormal types of speech in Nootka. In Sapir, Edward. Collected Writings of Edward Sapir in Language, Culture and Personality. Berkeley: University of California Press. P. 179-196.

Sasse, Hans-Jürgen (2001). Scales between nouniness and verbiness. In Language typology and language universals: An international Handbook. Vol. 1. Ed. by M. Haspelmath et al. Berlin; New York. P. 495-508.

Silverstein, Michael (1981). The Limits of Awareness. In Working Papers in Sociolinguistics. No. 84. Austin: Southwestern Educational Laboratory.

Talmy, Leonard (2000). Toward a Cognitive Semantics. Vol. I: Concept Structuring System. Cambridge, MA: MIT Press.

Walsh, Michael (1996). Vouns \& nerbs: A category Squish in Murrinh-Patha (Northern Australia). In Studies in Kimberley languages in honour of Howard Coate. Ed. by W. McGregor. München. P. 227-252.

Whorf, Benjamin Lee (1956). Language, Thought, and Reality. Cambridge: MIT Press. 


\title{
Преодолевая словоцентризм:
}

\section{на пути к новым основаниям философии языка}

\section{С.Ю. Бородай}

Институт философии РАН

Российская Федераџия, Москва

\begin{abstract}
Аннотация. В статье представлена попытка переосмыслить характерное для западной философии и бытового сознания понимание языка как «набора слов», соотнесенных с «объектами» внешней действительности. Против такого подхода приводятся следующие аргументы: понятие «слова» (как и само деление на морфологию и синтаксис) не имеет металингвистического статуса; классификация частей речи лингвоспецифична, так что прототипическая референциальная функция «существительного» не может претендовать на статус универсальной языковой функции; представление о языке как «наборе слов» отражает лишь специфическую метапрагматическую осведомленность носителей европейских языков. Рассматривая факты языкового разнообразия и языковых функций в свете грамматической типологии, автор показывает, что наиболее адекватной интерпретацией соотношения языка и действительности является такое понимание, которое характеризует язык как масштабный аппарат по принуждению к определенному изображению события. При этом подчеркивается фундаментальная специфичность грамматической структуры и узусных моделей каждой конкретной лингвистической системы. Для продвижения философского осмысления языка необходимо перейти от наивной схемы «слово - референция - объект» к более реалистичной схеме «язык (как набор морфосинтаксических паттернов концептуализации) - соотнесение - событие (как комплексная смысловая ситуация)».
\end{abstract}

Ключевые слова: философия языка, когнитивная лингвистика, лингвистическая типология, слово, референция.

Научная специальность: 09.00.00 - философские науки. 